\title{
Recurrent sick leave and resignation rates among female cancer survivors after return to work: the Japan sickness absence and return to work (J-SAR) study
}

Motoki Endo ${ }^{1 *}$, Yasuo Haruyama ${ }^{2}$, Go Muto ${ }^{3}$, Yuya Imai ${ }^{1}$, Kiyomi Mitsui ${ }^{4}$, Tetsuya Mizoue ${ }^{5}$, Hiroo Wada ${ }^{1}$, Gen Kobashi ${ }^{2}$ and Takeshi Tanigawa ${ }^{1}$

\begin{abstract}
Background: To date, there have not been any workforce-based Japanese cohort studies investigating work sustainability after return to work (RTW). The objective of this study was to investigate the post-RTW cumulative recurrent sick leave rate and cumulative resignation rate among female cancer survivors.

Methods: Among Japanese employees who were registered in the Japan sickness absence and return to work (J-SAR) study, the subjects were those female employees who returned to work after sick leave due to newly clinically diagnosed cancer (C01-C99; ICD-10), based on a physician's certificate, between 2000 and 2011. The last day of the follow-up period was December 31, 2012. The recurrent sickness leave rate and resignation rate were calculated using competing risk survival analysis.

Results: Of 223 cancer survivors, 61 took further physician-certified sick leave after their RTW. The median duration of the post-RTW work period among all cancer survivors was 10.6 years. The work continuance rates of the female cancer survivors were 83.2 and $60.4 \%$ at 1 and 5 years after they returned to work, respectively. There was a steep reduction in the work continuance rate during the first post-RTW year. There were considerable differences in the work continuance rate according to the primary cancer site. Cumulative recurrent sick leave rates of 11.8 and 28.9\% were seen at 1 and 5 years after the subjects returned to work. The cumulative resignation rate was 5.0 and $10.7 \%$ at 1 and 5 years after the subjects returned to work. Most recurrent sick leave occurred in the first year after the subjects returned to work, followed by the second year.
\end{abstract}

Conclusions: Sixty percent of female cancer survivors were still working at 5 years after returning to work, although the work continuance rates for different types of cancer varied significantly.

Keywords: Cancer survivors, Return to work (RTW), Recurrent sick leave, Resignation

\section{Background}

According to the statistics of the Ministry of Internal Affairs and Communication, Japan (2010), the working age population in Japan includes 81.3 million people; however, it is estimated that it will decrease in size by almost $50 \%$ in the next 50 years [1]. Currently, Japan is transitioning to a society where women, senior citizens,

\footnotetext{
*Correspondence: phdmotokiendo@gmail.com

'Department of Public Health, Juntendo University Faculty of Medicine, 2-1-1 Hongo, Bunkyo-ku, Tokyo 113-8421, Japan

Full list of author information is available at the end of the article
}

and foreigners will be indispensable to the employment market [2]. In many developed countries, the number of cancer patients in the working population is increasing, and the probability that workers will suffer from cancer is also rising [2-4]. In Japan, these phenomena are caused by the following four factors: the first factor is the increase in the number of senior citizens that are still working. It has been reported that some workers in their 60s develop cancer after becoming temporary workers after their mandatory retirement at 60 years old [1]. The second factor is an increase in the number

(c) The Author(s). 2019 Open Access This article is distributed under the terms of the Creative Commons Attribution 4.0 International License (http://creativecommons.org/licenses/by/4.0/), which permits unrestricted use, distribution, and 
of working women. In fact, the number of double-income households (in which both the husband and wife work) markedly exceeds the number of households that include full-time housewives [1]. The third factor is the increasing incidence of cancer among females, especially breast cancer, and the younger age of onset of cervical cancer [5]. The fourth factor is that the prognosis of cancer patients has improved due to the development of treatments that place less burden on the body [6].

As cancer survival rates have improved due to recent advances in cancer treatment, more cancer survivors are able to resume their everyday lives and return to work (RTW) during or after treatment $[3,7,8]$. While cancer is more likely to occur among the elderly, breast cancer and uterine cancer are common in people of working age [9].

In February 2016, the "guidelines for the support of therapy and working life in the Japanese workforce" were published by the Japanese Ministry of Health, Labour and Welfare [10]. As a result of the revision of the Cancer Control Act in December 2016, companies in Japan are required to support the reinstatement of employees with cancer [11].

While returning to work would seem to indicate that a cancer survivor has completely recovered from their illness and the adverse effects of treatment, it actually only demonstrates that their ability to perform their job has recovered to a level where they can be reinstated. After returning to work, cancer survivors often encounter difficulties associated with the balance between the demands of treatment and recovery and the requirements of the workplace [12-14]. Some cancer survivors continue to receive chemotherapy, whereas others suffer from cancer-related fatigue $(\mathrm{CrF})$, pain, functional impairment, and/or psychological distress $[15,16]$. Working after returning to work is extremely challenging for cancer patients, especially with regard to physical and mental health $[17,18]$.

Although a number of studies of cancer survivors have been carried out in Europe and the US, there have not been any workforce-based Japanese cohort studies investigating the frequency of recurrent sick leave or resignations among female cancer survivors that they RTW [15, 19-22]. It is very important to clarify the work sustainability of female cancer survivors that RTW, as females in their $20 \mathrm{~s}$ to $40 \mathrm{~s}$ are more likely to suffer from cancer than their male counterparts [5].

The objective of this study was to investigate the cumulative recurrent sick leave rate and cumulative resignation rate after Japanese female cancer survivors RTW and to analyze predictors of recurrent sick leave, resignation between different cancers. This study is the first cohort study to examine the work sustainability of cancer-affected female employees in Japan.

\section{Methods \\ Subjects}

The Japan sickness absence and return to work study (J-SAR study) was a retrospective, observational cohort study conducted in Japan. The J-SAR study analyzed data regarding sick leave that were registered in the health data system of a private occupational health center. This occupational health center had signed occupational health service with the following companies: regional, international telecommunication, big data and mobile services (installing and maintaining telephones, faxes, telegrams, internet systems, cell phones), logistics, energy, and construction etc., as described elsewhere $[15,23-28]$. In 2000, about 68, 000 employees were working for these companies on a full-time basis. In this study, we extracted the data of all employees who had taken sick leave due to newly diagnosed cancer between January 1st, 2000, and December 31st, 2011.

\section{Sickness absence system}

In Japan, there is no law insuring sickness absence for employees who are not able to work. To our knowledge, almost all large Japanese companies have their own sickness insurance system for employees. The time limit for sickness absence varies depending on the company. In the Japanese sickness absence system, part-time sickness absence combined with part-time work is not so common. The fact is that many small and medium-sized enterprises in Japan do not have such an established sickness insurance system. We guess that cancer survivors who work at small and medium-sized enterprises have no choice but to quit because of their companies' economic circumstances, among other factors. On the other hand, this Japanese company group has more improved sickness absence system and RTW system than other companies, as described in our previous studies [15, 23-28].

\section{Inclusion criteria}

The subject inclusion criteria for this study were as follows: female employees, aged 18 to 60 years, who returned to work after their first period of sick leave due to clinically diagnosed cancer (C01-C99; ICD-10) based on a physician's certificate between January 1st, 2000, and December 31st, 2011. Two hundred forty-five female employees had sick leave due to cancer newly during the duration, as described in our previous study [15]. Of these female cancer survivors, 223 returned to work. Based on these inclusion criteria, the first period of sick leave was not a period of recurrent sick leave because employees who had suffered previous episodes of sick leave due to cancer before 31 December 1999 were not included in this study. The medical ethics committee of Juntendo University informed us that ethical 
approval was not required because the data were existing data that were anonymous and impossible to concatenate, and no associated correspondence table exists.

\section{Statistical analysis}

The work continuance rate was estimated via Kaplan-Meier survival analysis. Numbers of person-days were calculated based on the follow-up period. The day used to measure the beginning of the follow-up period was the first day of the subject's RTW after their sick leave due to cancer. In this study, the data were censored at the end of the follow-up period (December 31, 2012) or the day of retirement (March 31 of the year that the subject became 60 years old), whichever came first. The event day for this analysis was the first day of recurrent sick leave due to any physician-certified illness or the day of resignation before retirement. Deaths were analyzed as "recurrent sick leave". During the followup period, 12 female employees died after RTW.

Cumulative recurrent sick leave and resignation rates were calculated via competing risk survival analysis [29]. A survival analysis with competing risks was performed using EZR, which is statistical analysis software provided by CRAN (The Comprehensive $\mathrm{R}$ Archive Network) [30].

\section{Results}

In total, 223 female employees returned to work after their first period of sick leave due to cancer. The subjects' characteristics are shown in Table 1. Among these employees, breast cancer was the most common type of cancer (ICD-10, C50; $n=90$ ). The second most common type of cancer was female genital malignancy, which included cancer of the uterus $(n=47)$ and ovarian cancer $(n=17)$. The third most common type of cancer was gastric cancer $(n=18)$, followed by lung cancer $(n=16)$. The other types of cancer $(n=35)$ seen among the employees included colon cancer $(n=5)$ and esophageal cancer $(n=3)$. The subjects' mean age on the initial day of their sick leave was 48.2 years old. Just after returning to work, 185 cancer survivors $(83.0 \%$ of RTW employees) had their work schedules reduced based on OP certificates, and 38 cancer survivors were able to work full-time.

After returning to work, 61 subjects (27.3\%) experienced further periods of sick leave (recurrent sick leave) due to medical reasons, which were certified by their physicians. Of these 61 employees, 43 experienced recurrent sick leave due to their original cancer, 4 developed new types of cancer (other cancer), 4 suffered from common mental disorders, and 3 suffered fractures. Twentytwo cancer survivors resigned before reaching retirement age ( 60 years). Among all cancer survivors, the median duration of the period of work after the subjects initially returned to work was 10.6 years. During the follow-up period, 12 female employees died after the day of RTW. Of the 12 deaths, 9 employees died within the period of recurrent sick leave.

\section{Work continuance rates, recurrent sick leave, and reassignment after returning to work}

According to Kaplan-Meier survival estimates, the work continuance rate of the female cancer survivors was $88.2 \%$ at 6 months, $83.2 \%$ at 1 year, $73.1 \%$ at 2 years, $69.6 \%$ at 3 years, $64.2 \%$ at 4 years, and $60.4 \%$ at 5 years after they initially returned to work, as shown in Fig. 1. Figure 2 shows that there was a steep decrease in the work continuance rate during the first year after the subjects returned to work. It should be noted that the work

Table 1 Basic characteristics of the subjects in this study

\begin{tabular}{|c|c|c|c|c|c|c|c|c|c|c|}
\hline & $n$ & $\begin{array}{l}\text { Mean } \\
\text { age } \\
( \pm S D)\end{array}$ & $\begin{array}{l}\text { Urban / } \\
\text { Rural (n) }\end{array}$ & $\begin{array}{l}\text { Desk / manual } \\
\text { worker }(n)\end{array}$ & $\begin{array}{l}\text { 1. Experienced } \\
\text { RSA (n) (\%) }\end{array}$ & $\begin{array}{l}2 . \\
\text { Resigned } \\
(\mathrm{n})(\%)\end{array}$ & $\begin{array}{l}3 . \\
\text { Censored } \\
(n)(\%)\end{array}$ & $\begin{array}{l}\text { 1-year work } \\
\text { survival rate (\%) }\end{array}$ & $\begin{array}{l}\text { 5-year work } \\
\text { survival rate (\%) }\end{array}$ & $\begin{array}{l}\text { Median time to } \\
\text { work disability } \\
\text { (years) }\end{array}$ \\
\hline \multicolumn{11}{|l|}{ Cancer site } \\
\hline $\begin{array}{l}\text { Breast } \\
\text { cancer }\end{array}$ & 90 & $48.4 \pm 6.6$ & $68 / 22$ & $89 / 1$ & $22(24.4 \%)$ & $9(10.0 \%)$ & $59(65.6 \%)$ & 82.9 & 63.4 & N.A. \\
\hline $\begin{array}{l}\text { Female } \\
\text { genitals }\end{array}$ & 64 & $46.6 \pm 7.3$ & $48 / 16$ & $64 / 0$ & 19 (29.7\%) & $1(1.6 \%)$ & $44(68.8 \%)$ & 87.3 & 67.8 & N.A. \\
\hline $\begin{array}{l}\text { Gastric } \\
\text { cancer }\end{array}$ & 18 & $52.4 \pm 5.1$ & $11 / 7$ & $17 / 1$ & $2(11.1 \%)$ & $3(16.7 \%)$ & $13(72.2 \%)$ & 83.3 & 63.1 & N.A. \\
\hline $\begin{array}{l}\text { Lung } \\
\text { cancer }\end{array}$ & 16 & $52.1 \pm 4.5$ & $16 / 0$ & $15 / 1$ & $5(31.3 \%)$ & $7(43.8 \%)$ & $4(25.0 \%)$ & 75.0 & 31.3 & 3.0 \\
\hline $\begin{array}{l}\text { Other } \\
\text { cancer }\end{array}$ & 35 & $46.4 \pm 8.4$ & $29 / 6$ & $31 / 1$ & $13(37.1 \%)$ & $2(5.7 \%)$ & $20(57.1 \%)$ & 80.0 & 55.1 & N.A. \\
\hline $\begin{array}{l}\text { Total } \\
\text { Stroke }\end{array}$ & 223 & $48.2 \pm 7.1$ & $172 / 51$ & $216 / 4$ & $61(27.3 \%)$ & $22(9.9 \%)$ & $\begin{array}{l}140 \\
(62.8 \%)\end{array}$ & 83.2 & 60.4 & 10.6 \\
\hline
\end{tabular}

Female genital malignancy included cancer of the uterus $(n=47)$ and ovarian cancer $(n=17)$

Other cancer included colon cancer $(n=5)$ and esophageal cancer $(n=3)$

RSA Recurrent sick leave 


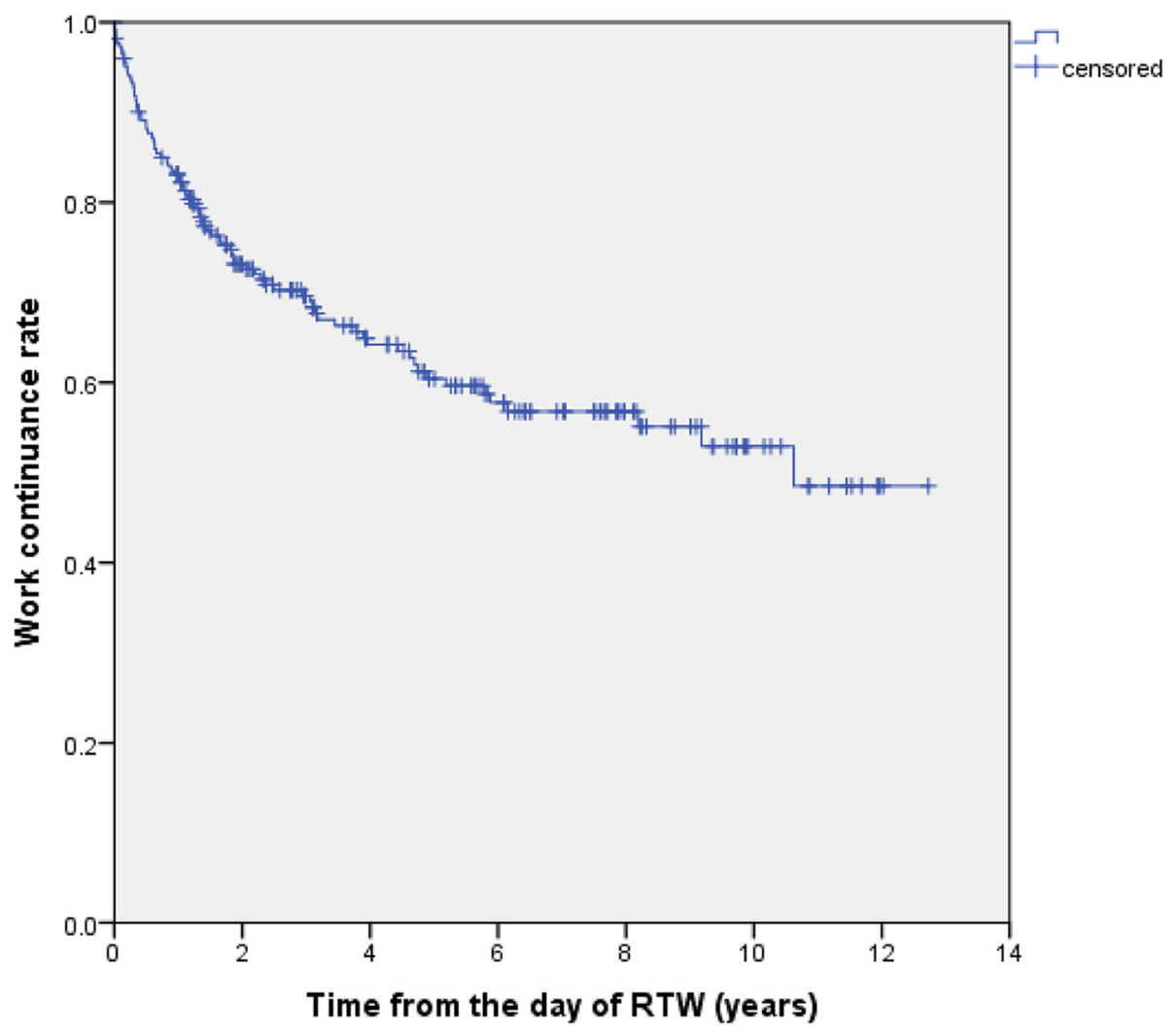

Fig. 1 Work continuance rate from the day of RTW according to Kaplan-Meier survival analysis

continuance rate varied markedly according to the primary cancer site (Fig. 2). However, there were no statistically significant difference between different cancers, as for recurrent sick leave and resignation.

The work continuance rate of the subjects with breast cancer patients was $82.9 \%$ at 1 year, $73.8 \%$ at 2 years, and $63.4 \%$ at 5 years. The work continuance rate of the subjects with lung cancer was $70.5 \%$ at 1 year, $62.5 \%$ at 2 years, and $31.3 \%$ at 5 years, and these values were lower than those of the other types of cancer. As shown in Fig. 3, in the survival analysis of competing risks, the cumulative recurrent sick leave rate was shown to be $9.1 \%$ at 6 months, $11.8 \%$ at 1 year, $19.5 \%$ at 2 years, $21.9 \%$ at 3 years, $25.9 \%$ at 4 years, and $28.9 \%$ at 5 years after the subjects returned to work. The cumulative resignation rate was $2.7 \%$ at 6 months, $5.0 \%$ at 1 year, $7.4 \%$ at 2 years, $8.5 \%$ at 3 years, $9.9 \%$ at 4 years, and $10.7 \%$ at 5 years after the subjects returned to work, as shown in Fig. 3.

\section{Discussion}

As far as we know, this is the first longitudinal cohort study to investigate the work sustainability of female cancer survivors after they RTW. We found that about $60 \%$ of female cancer survivors were still working at 5 years after their RTW, although the work continuance rate differed significantly among different cancer types.
In particular, the lung cancer patients exhibited had the lowest work continuance rate. Though there were no statistically significant difference between different cancers, as for recurrent sick leave and resignation, that could be caused by the rather small sample in this study.

The main work-related problems experienced by female cancer survivors after they RTW are as follows: the first is recurrent sick leave due to a physician-certified medical reason (including death). As shown in Fig. 2, we found that recurrent sick leave most commonly occurred in the first year after the cancer survivors returned to work, followed by the second year. Of the female cancer survivors who required recurrent sick leave $(n=61), 25.0,32.4$, and $53.6 \%$ required such leave within 6 months, 1 year, and 2 years of their RTW, respectively. The competing risk curve for recurrent sick leave plateaus at 5 years after a cancer survivor returns to work, and hence, is very similar in shape to the Kaplan-Meier curve of recurrent sick leave due to depression produced in a previous study [26].

The second problem experienced by female cancer survivors is having to resign before they reach retirement age (60 years old). In the present study, the cumulative resignation rate was unexpectedly low. The survival curve of the cumulative resignation rate remained below $10 \%$ until 4 years after the subjects returned to work. Of all the postRTW resignations, $17.9,33.1,49.0,56.2,65.6$, and $70.9 \%$ 


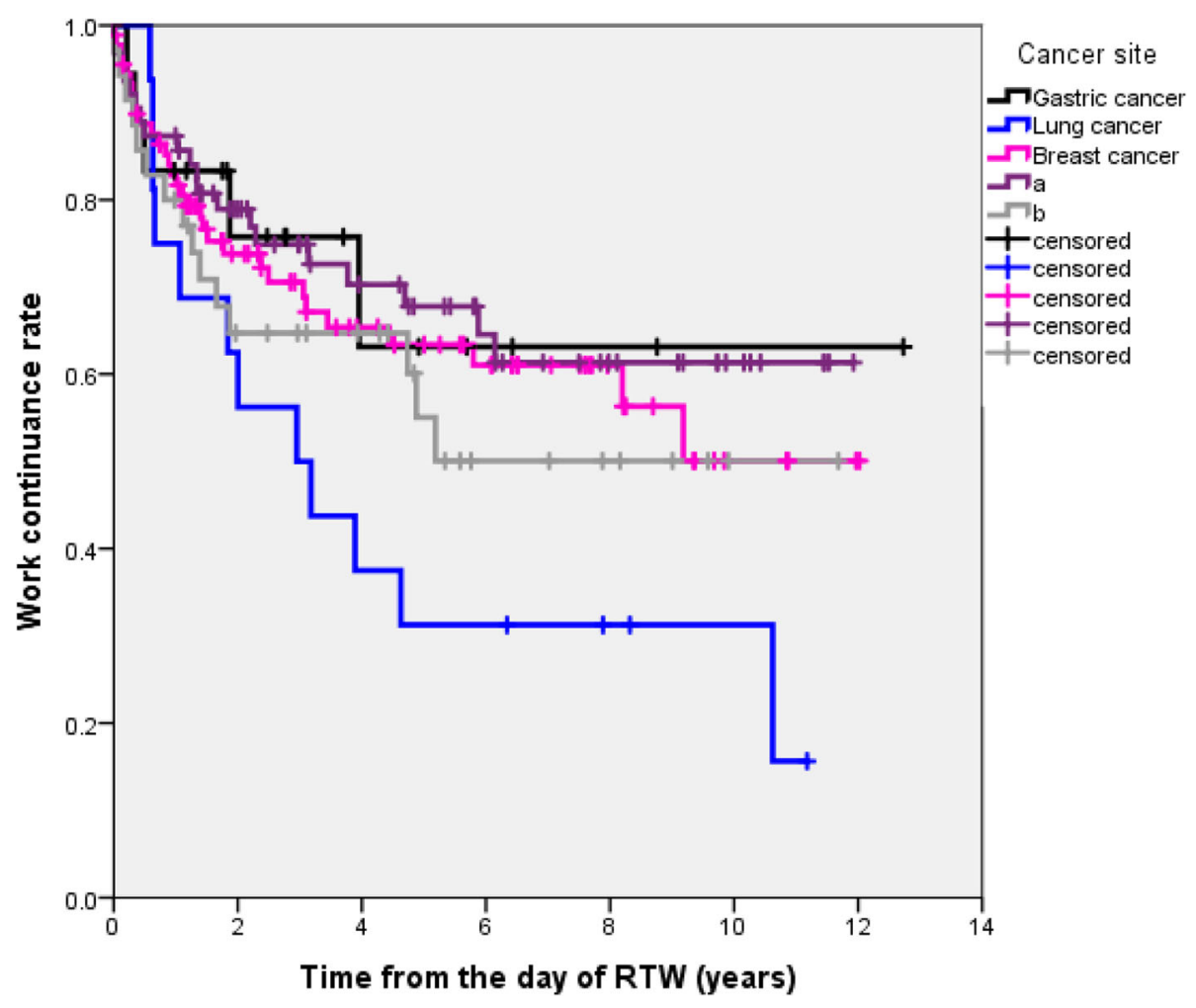

Fig. 2 Work continuance rate from the day of RTW stratified by cancer site. a Female genital malignancy included cancer of the uterus ( $n=47)$ and ovarian cancer $(n=17)$. b Other cancer included colon cancer $(n=5)$ and esophageal cancer $(n=3)$

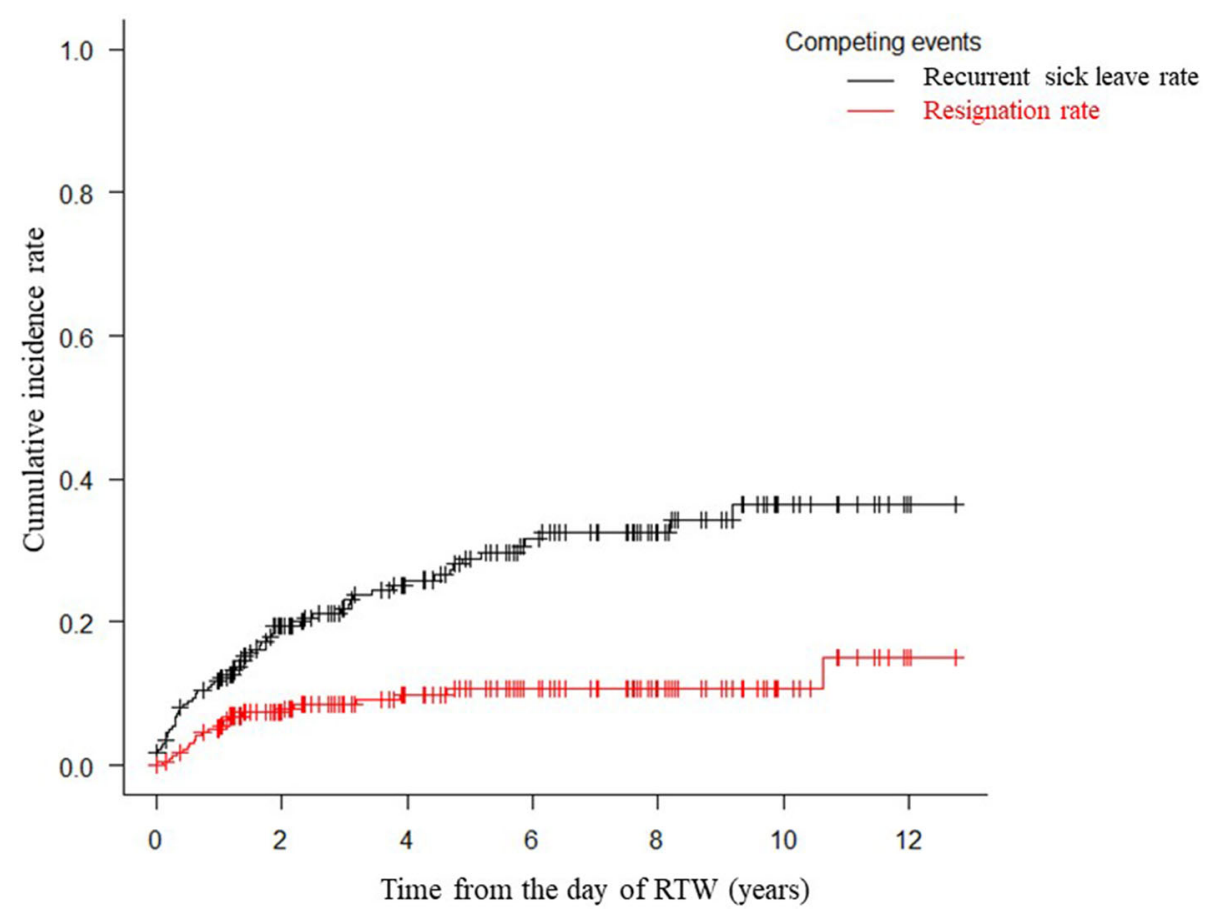

Fig. 3 Post-RTW recurrent sick leave and resignation rates according to competing risk analysis 
had occurred within 6 months, 1 year, 2 years, 3 years, 4 years, and 5 years after the subjects returned to work. Short et al. reported that about $10 \%$ of cancer survivors resigned from their jobs within a 4-year period because of cancer-related factors [31]. Stewart et al. reported that about $12.5 \%$ of breast cancer survivors quit their jobs before retirement as a result of cancer [32].

Female cancer survivors' work continuance rates (60.4\%) at 5 years after the RTW day were higher than male cancer survivors (48.5\%) [27]. We speculated that the probability of more male cancer survivors who had cancer sites of lower work continuance rates (for example, lung cancer, hepatic cancer, pancreatic cancer, esophageal cancer) was higher than female. As for comparing work continuance rates by cancer sites, the female work continuance rates $63.1 \%$ of gastric cancer at 5 years after RTW was almost same as male (62.1\%). However, the female work continuance rates of lung cancer (31.3\%) at 5 years after RTW were higher than male (12.1\%). As the 5year relative survival rates of lung cancer among female, male cancer survivors were $43.2,27.0 \%$, respectively, the epidemiology of lung cancer tissue types might affect the difference in the work continuance rates between women and men [9] While only 4 employees in the present study took recurrent sick leave due to mental disorders (certified by psychiatrists), cancer survivors often suffer from more severe anxiety and depression than non-cancer survivors [33]. Cancer survivors might fear the recurrence or progression of their disease, which might act as a strong stressor, even years after the initial diagnosis [34]. While employees with cancer struggle to stay in work, raise their children, and live a normal life, the work sustainability of female cancer survivors tends to be lower than that of male cancer survivors [35]. Gudbergsson et al. reported that female cancer survivors experienced more job-related strain than males [36]. In addition, De Boer et al. reported that it took more time for female cancer survivors to recover their work abilities than male cancer survivors [20]. Our study showed that the work continuance rate of female cancer survivors was higher than that of male cancer survivors, while the survival rate of Japanese female cancer survivors was estimated to be higher than that of Japanese male cancer survivors according to the Japan cancer registry [27, 37]. As for the social support provided to cancer survivors with work-related disabilities, it varies from country to country. In the Netherlands, cancer survivors can apply for a work disability benefit after being on sick leave for 2 years, whereas working Japanese cancer survivors are not supported by similar laws or government recommendations, and so the support available depends on the employee's company $[2,38]$. In a study by Bradley et al., the proportion of cancer survivors that underwent a partial RTW was lower than in the present study (80\%) [39]. The female cancer survivors in the current study were supported by OP, who encouraged the use of adaptations to facilitate partial RTW because they worked in large companies. We speculate that, more female cancer survivors would be able to continue their work after RTW, if they are supported by various employment support even in small and medium-sized businesses. This study provides useful epidemiological information about RTW support, especially for cancer patients in small and medium-sized enterprises [15]. However, it should always be noted that studies can differ in terms of their design, methodology, and the social circumstances of their subjects $[40,41]$.

\section{Strengths and limitations}

As for the strengths of this study, it was the first longitudinal study (it covered a period of $>10$ years) to investigate the frequencies of recurrent sick leave and resignation after female cancer survivors RTW. Secondly, the registered sick leave data analyzed in this study were based on physicians' certificates, which increases the study's validity.

As for the limitations of this study, the results of this study should be interpreted carefully. First, the patients' medical files were not available, and so we did not have any information about the treatments the subjects received, the side effects previous treatments induced, or cancer-related symptoms. As a future task, the effects of clinical factors (e.g., surgery, chemotherapy, and radiotherapy) on work sustainability among female cancer survivors should beconsidered. Especially, $\mathrm{CrF}$ is known to be one of the most influential factors for work sustainability, caused by surgery, chemotherapy, radiotherapy, and hormone treatment [42-44]. Secondly, all of the study subjects worked at large companies; thus, it might be difficult to generalize the results of this study to small and medium-sized enterprises. Thirdly, data of sick leave and resignation among other workers in the companies were not available. Fourthly, this RTW system in which the company decides who are allowed to work, might include study participants with higher work ability than in systems in which it is up to the employee to decide whether she is fit to work. Fifthly, as resignation after RTW was evaluated as work discontinuation in this study, some subjects stopped working for the company being studied, but continued working elsewhere.

\section{Conclusion}

Sixty percent of female cancer survivors were still working at 5 years after they returned to work, although the work continuance rate differed significantly among the various types of cancer. Recurrent sick leave occurred most frequently in the first year after the subjects returned to work, followed by the second year. 


\section{Abbreviations}

CrF: Cancer-related fatigue; J-SAR study: The Japan sickness absence and return to work study; OP: Occupational Physicians; RSA: Recurrent sickness absence; RTW: Return to work

\section{Acknowledgements}

Not applicable.

\section{Authors' contributions}

$M E, Y H, G M, Y I, K M, T M, H W$, and GK created the research plans for this study, collected previous studies, and reviewed the manuscript. TT intellectually revised the manuscript. All authors have read and approved the manuscript, and ensure that this is the case.

\section{Funding}

The authors declare that this study was funded by Grants from the Japanese Ministry of Health, Labour and Welfare (Research Grant (Gan-taisaku-ippan-012) to Motoki Endo. The funders had no role in study design, data collection and analysis, decision to publish, or preparation of the manuscript.

\section{Availability of data and materials}

It is not possible to share J-SAR study data publicly. The datasets analyzed during the current study are not publicly available due to this company group's request. We had J-SAR study data supporting the results reported in the article. The J-SAR study analyzed data regarding sick leave that were registered in the health data system of a private occupational health center, which belongs to a large-scale Japanese company group. J-SAR study data analyzed during this study are included in these published articles [15, 23-28].

\section{Ethics approval and consent to participate}

The medical ethics committee of Juntendo University informed us that ethical approval and consent was not required and because the data were existing data that were anonymous and impossible to concatenate, and no associated correspondence table exists, according to national guidelines [45].

\section{Consent for publication}

Not applicable.

\section{Competing interests}

The authors declare that they have no competing interests.

\section{Author details}

'Department of Public Health, Juntendo University Faculty of Medicine, 2-1-1 Hongo, Bunkyo-ku, Tokyo 113-8421, Japan. ${ }^{2}$ Department of Public Health, Dokkyo University School of Medicine, Tochigi, Japan. ${ }^{3}$ Department of Epidemiology and Environmental Health, Juntendo University Faculty of Medicine, Tokyo, Japan. ${ }^{4}$ Department of Hygiene, Public Health and Preventive Medicine, Showa University, Tokyo, Japan. ${ }^{5}$ Department of Epidemiology and Prevention, Center for Clinical Sciences, National Center for Global Health and Medicine, Tokyo, Japan.

\section{Received: 31 March 2019 Accepted: 16 August 2019}

\section{Published online: 11 September 2019}

\section{References}

1. Japan S: Result of the population estimates. 2017.

2. Endo M. Work with cancer in Japan. Int J Cancer Stud Res. 2017;6(1e):1-2.

3. Aziz NM. Cancer survivorship research: state of knowledge, challenges and opportunities. Acta Oncol. 2007;46(4):417-32.

4. Feuerstein M. Work and cancer survivors: Springer; 2011. https://www. springer.com/gp/book/9780387720401.

5. Hori M, Matsuda T, Shibata A, Katanoda K, Sobue T, Nishimoto H, Japan Cancer Surveillance Research G. Cancer incidence and incidence rates in Japan in 2009: a study of 32 population-based cancer registries for the monitoring of cancer incidence in Japan (MCIJ) project. Jpn J Clin Oncol. 2015;45(9):884-91.

6. Hoffman B. Cancer survivors at work: a generation of progress. CA Cancer J Clin. 2005;55(5):271-80
7. Verdecchia A, Francisci S, Brenner H, Gatta G, Micheli A, Mangone L, Kunkler I, Group E-W. Recent cancer survival in Europe: a 2000-02 period analysis of EUROCARE-4 data. Lancet Oncol. 2007;8(9):784-96.

8. Leensen MCJ, Groeneveld IF, Rejda T, Groenenboom P, van Berkel S, Brandon T, de Boer A, Frings-Dresen MHW. Feasibility of a multidisciplinary intervention to help cancer patients return to work. Eur J Cancer Care (Engl). 2017. https://onlinelibrary.wiley.com/doi/abs/1 $0.1111 /$ ecc. 12690

9. Ito $\mathrm{Y}$, Miyashiro I, Ito H, Hosono S, Chihara D, Nakata-Yamada K, Nakayama M, Matsuzaka M, Hattori M, Sugiyama $H$, et al. Long-term survival and conditional survival of cancer patients in Japan using population-based cancer registry data. Cancer Sci. 2014;105(11):1480-6.

10. Ministry of Health Labor W, Japan. Jigyojou ni okeru tiryo to syokugyouseikatu ni okeru ryouritusien ni okeru gaidorain (Guideline for support for therapy and work life in Japanese workforce). 2016

11. Cancer Control Act, Japan. 2016. https://www.mhlw.go.jp/file/05-Shingikai-1 0904750-Kenkoukyoku-Gantaisakukenkouzoushinka/0000146908.pdf.

12. Amir Z, Moran T, Walsh L, Iddenden R, Luker K. Return to paid work after cancer: a British experience. J Cancer Surviv. 2007;1(2):129-36.

13. Verbeek J, Spelten E, Kammeijer M, Sprangers M. Return to work of cancer survivors: a prospective cohort study into the quality of rehabilitation by occupational physicians. Occup Environ Med. 2003;60(5):352-7.

14. Brown RF, Owens M, Bradley C. Employee to employer communication skills: balancing cancer treatment and employment. Psychooncology. 2013;22(2):426-33.

15. Endo M, Haruyama Y, Takahashi M, Nishiura C, Kojimahara N, Yamaguchi N. Returning to work after sick leave due to cancer: a 365-day cohort study of Japanese cancer survivors. J Cancer Surviv. 2015.

16. Karki A, Simonen R, Malkia E, Selfe J. Impairments, activity limitations and participation restrictions 6 and 12 months after breast cancer operation. J Rehabil Med. 2005;37(3):180-8

17. Feuerstein M, Todd BL, Moskowitz MC, Bruns GL, Stoler MR, Nassif T, Yu X. Work in cancer survivors: a model for practice and research. J Cancer Surviv. 2010;4(4):415-37.

18. Short PF, Vasey JJ, Belue R. Work disability associated with cancer survivorship and other chronic conditions. Psychooncology. 2008;17(1):91-7.

19. Mehnert A, Koch U. Predictors of employment among cancer survivors after medical rehabilitation--a prospective study. Scand J Work Environ Health. 2013:39(1):76-87.

20. de Boer AG, Verbeek JH, Spelten ER, Uitterhoeve AL, Ansink AC, de Reijke TM, Kammeijer M, Sprangers MA, van Dijk FJ. Work ability and return-towork in cancer patients. Br J Cancer. 2008;98(8):1342-7.

21. de Boer AG, Bruinvels DJ, Tytgat KM, Schoorlemmer A, Klinkenbijl JH, FringsDresen $\mathrm{MH}$. Employment status and work-related problems of gastrointestinal cancer patients at diagnosis: a cross-sectional study. BM Open. 2011;1(2):e000190.

22. Torp S, Nielsen RA, Gudbergsson SB, Fossa SD, Dahl AA. Sick leave patterns among 5-year cancer survivors: a registry-based retrospective cohort study. J Cancer Surviv. 2012;6(3):315-23.

23. Endo M, Sairenchi T, Kojimahara N, Haruyama Y, Sato $Y$, Kato R, Yamaguchi N. Sickness absence and return to work among Japanese stroke survivors: a 365-day cohort study. BMJ Open. 2016;6(1):e009682.

24. Endo M, Haruyama Y, Mitsui K, Muto G, Nishiura C, Kuwahara K, Wada H, Tanigawa T. Durations of first and second periods of depression-induced sick leave among Japanese employees: the Japan sickness absence and return to work (J-SAR) study. Ind Health. 2018.

25. Endo M, Muto T, Haruyama Y, Yuhara M, Sairenchi T, Kato R. Risk factors of recurrent sickness absence due to depression: a two-year cohort study among Japanese employees. Int Arch Occup Environ Health. 2015;88(1):75-83.

26. Endo M, Haruyama Y, Muto T, Yuhara M, Asada K, Kato R. Recurrence of sickness absence due to depression after returning to work at a Japanese IT company. Ind Health. 2013;51(2):165-71.

27. Endo M, Haruyama Y, Muto G, Kiyohara K, Mizoue T, Kojimahara N, Yamaguchi N. Work sustainability among male cancer survivors after returning to work. J Epidemiol. 2018;28(2):88-93.

28. Endo M, Haruyama Y, Muto G, Yokoyama K, Kojimahara N, Yamaguchi N. Employment sustainability after return to work among Japanese stroke survivors. Int Arch Occup Environ Health. 2018;91(6):717-24.

29. Scrucca L, Santucci A, Aversa F. Competing risk analysis using R: an easy guide for clinicians. Bone Marrow Transplant. 2007:40(4):381-7.

30. Kanda $Y$. Investigation of the freely available easy-to-use software 'EZR' for medical statistics. Bone Marrow Transplant. 2013;48(3):452-8. 
31. Short PF, Vasey JJ, Tunceli K. Employment pathways in a large cohort of adult cancer survivors. Cancer. 2005;103(6):1292-301.

32. Stewart DE, Cheung AM, Duff S, Wong F, McQuestion M, Cheng T, Purdy L, Bunston T. Long-term breast cancer survivors: confidentiality, disclosure, effects on work and insurance. Psychooncology. 2001;10(3):259-63.

33. Gudbergsson SB, Fossa SD, Borgeraas E, Dahl AA. A comparative study of living conditions in cancer patients who have returned to work after curative treatment. Support Care Cancer. 2006;14(10):1020-9.

34. Hodges $\sqcup$, Humphris GM. Fear of recurrence and psychological distress in head and neck cancer patients and their carers. Psychooncology. 2009;18(8):841-8.

35. Inhestern L, Beierlein V, Bultmann JC, Moller B, Romer G, Koch U, Bergelt C Anxiety and depression in working-age cancer survivors: a register-based study. BMC Cancer. 2017;17(1):347.

36. Gudbergsson SB, Fossa SD, Sanne B, Dahl AA. A controlled study of job strain in primary-treated cancer patients without metastases. Acta Oncol. 2007;46(4):534-44.

37. Cancer Information Service NCC, Japan. Cancer Registry and Statistics.

38. van Muijen P, Duijts SF, Kornet-van der Aa DA, van der Beek AJ, Anema JR. Work disability assessment of cancer survivors: insurance physicians' perspectives. Occup Med (Lond). 2015;65(7):558-63.

39. Bradley CJ, Bednarek HL. Employment patterns of long-term cancer survivors. Psychooncology. 2002;11(3):188-98.

40. Roelen CA, Koopmans PC, Groothoff JW, van der Klink JJ, Bultmann U. Sickness absence and full return to work after cancer: 2-year follow-up of register data for different cancer sites. Psychooncology. 2011;20(9):1001-6.

41. Hensing G. Swedish council on technology assessment in health care (SBU). Chapter 4. Methodological aspects in sickness-absence research. Scand J Public Health Suppl. 2004;63:44-8.

42. Joachim Weis MH. Cancer-related fatigue; 2015.

43. Ahn E, Cho J, Shin DW, Park BW, Ahn SH, Noh DY, Nam SJ, Lee ES, Yun YH. Impact of breast cancer diagnosis and treatment on work-related life and factors affecting them. Breast Cancer Res Treat. 2009;116(3):609-16.

44. Mehnert A. Employment and work-related issues in cancer survivors. Crit Rev Oncol Hematol. 2011;77(2):109-30.

45. Ministry of Health LaW, Japan: Hito wo taisyotosuru igaku kenkyu ni kansuru rinri shishin (in Japanese). 2017

\section{Publisher's Note}

Springer Nature remains neutral with regard to jurisdictional claims in published maps and institutional affiliations.

Ready to submit your research? Choose BMC and benefit from:

- fast, convenient online submission

- thorough peer review by experienced researchers in your field

- rapid publication on acceptance

- support for research data, including large and complex data types

- gold Open Access which fosters wider collaboration and increased citations

- maximum visibility for your research: over $100 \mathrm{M}$ website views per year

At BMC, research is always in progress.

Learn more biomedcentral.com/submissions 